\title{
Reactivity in Radical Polymerization of Poly(2-oxazoline) Macromonomers
}

\author{
Yasuo Shimano, ${ }^{\dagger}$ Kumiko Sato, and Shiro KobaYashi* \\ Department of Chemical and Biological Engineering, Hachinohe National College of Technology, \\ Tamonoki, Hachinohe 039-1192, Japan \\ * Department of Materials Chemistry, Graduate School of Engineering, Kyoto University. \\ Kyoto 606-8501, Japan
}

(Received June 5, 1998)

\begin{abstract}
Reactivity in radical homopolymerization of vinylbenzyl-ended poly(2-alkyl-2-oxazoline) macromonomers (VB-PROZO- $n ; n$ (degree of polymerization) $=3-34$ ) and methacryloyl-ended macromonomers (MA-PROZO- $n$; $n=4-34)$ was examined at $60^{\circ} \mathrm{C}$ in $\mathrm{CD}_{3} \mathrm{CN}, \mathrm{CDCl}_{3}$, or $\mathrm{D}_{2} \mathrm{O}$ using $2,2^{\prime}$-azobis(isobutyronitrile) (in organic solvents) or 2,2'azobis(2-amidinopropane) dihydrochloride (in $\mathrm{D}_{2} \mathrm{O}$ ) as initiator. $\mathrm{R}$ was $\mathrm{Me}, \mathrm{Bu}$, or $n$-octyl $(\mathrm{Oc})$ group. In $\mathrm{CD} \mathrm{CN}_{3}(\mathrm{R}=\mathrm{Me}$, $\mathrm{Bu}$ ), macromonomers were polymerized faster with increase in $n$. Higher $R_{\mathrm{p}}$ was observed for Bu group and MA end group than Me group or VB end group, respectively. In $\mathrm{CDCl}_{3}$, polymerization of VB-ended POcOZO macromonomers showed higher $R_{\mathrm{p}}$ than PBuOZO macromonomers. The rate increased with in $n$, whereas, polymerization of MA-ended POcOZO macromonomers showed lower $R \mathrm{p}$ than $\mathrm{PBuOZO}$ macromonomers of similar $n$, and rate decreased with increase in $n$. In $\mathrm{D}_{2} \mathrm{O}$, PMeOZO macromonomers were polymerized 9 to 14 times faster than $\mathrm{CD}_{3} \mathrm{CN}$. Kinetic orders of monomer concentration were 1.55 to 1.73 in organic solvents, while nearly 1.0 in water, and those of initiator concentration were close to 0.5 in $\mathrm{CD}_{3} \mathrm{CN}$. $R_{\mathrm{p}}$ is thus affected by carbon number of acyl side chains in PROZO and by $n$, and $\mathrm{D}_{2} \mathrm{O}$ increases enormously $R_{\mathrm{p}}$ of PMeOZO macromonomers by micelle formation.

KEY WORDS Macromonomers / Polyoxazoline / Radical Polymerization / Kinetics / Reactivity /
\end{abstract}

Cationic ring-opening polymerization of 2-alkyl-2oxazoline (ROZO) gives poly(2-alkyl-2-oxazoline) (PRO$\mathrm{ZO})$ having poly ( $N$-acylethylenimine) structure. PROZO can be regarded as a polymer homologue of polar aprotic solvents such as $N, N$-dimethylacetamide, exhibiting hydrophilic $(\mathrm{R}=\mathrm{Me}, \mathrm{Et})$ or hydrophobic (carbon number of $\mathrm{R} \geq 4$ ) properties. ${ }^{1}$ Macromonomers of PROZO, e.g., styryl- ${ }^{2}$, methacryloyl- ${ }^{3}$, and vinylester-terminated ${ }^{4}$ macromonomers have been synthesized using living polymerization of ROZO.

Macromonomers possess large importance and potential as building block for functional polymeric materials. Copolymerization with small-sized monomers produces graft copolymers with well-defined structure, and homopolymerization forms star-like or comb-like polymers. In contrast to polymerization of small monomers, polymerization systems of macromonomers have the following characteristics; (1) propagation reactions are polymer-polymer reactions, (2) concentrations of polymerizable end groups are low, (3) viscosity of polymerization systems is high from the initial stage of the reaction, ${ }^{5}$ and (4) segment density around the propagating species is high. ${ }^{5}$ These factors (1) - (4) have been found to affect greatly polymerization rates and molecular weights of poly(macromonomer)s. ${ }^{5 \text { ab, } 6}$ Radical copolymerizations of PROZO macromonomers produce micron or submicron-size polymer particles utilizing macromonomers as stabilizer or emulsifier, ${ }^{7}$ and form amphiphilic polymers from hydrophilic macromonomers and hydrophobic small monomers, i.e., styrene and methyl methacrylate (MMA). ${ }^{8}$ It is essential to know the characteristics of macromonomer reactivity in polymerization to obtain well-defined polymers. Many studies on copolymerizations ${ }^{6,9}$ and homopolymeriza-

\footnotetext{
† To whom correspondence should be addressed.
}

tions $^{2 b, 5,6}$ of macromonomers have been reported mainly in radical polymerization. The factor predominating polymerizability of macromonomers in copolymerization is primarily chemical reactivity of polymerizable end groups. ${ }^{2 \mathrm{~b}, 5 \mathrm{ab}, 10}$

Homopolymerization of PROZO macromonomers has not been reported so far for radical and ionic polymerizations. Polymerizability of PROZO macromonomers is of interest first in radical homopolymerization. Homopolymerization may be strongly subject to solvent effect, since macromonomers with polymer homologue structure of aprotic amide solvent can possess hydrophilic or hydrophobic nature. Consequently, polymerization behavior of macromonomers in organic solvents and/or water is of interest. In radical polymerization of poly(ethylene oxide) macromonomers in water, Ito and co-workers propose the micellar polymerization. ${ }^{5 \mathrm{~b}}$ Polymerization of macromonomers with long side chains has not been reported extensively. PROZO macromonomers with long acyl groups can easily be obtained and acyl side chains may affect sterically reactivity in growing sites and/or polymerizable end groups such as by increasing segment density. This paper reports reactivity in radical homopolymerization of vinylbenzyl- and methacryloyl-terminated PROZO macromonomers $(\mathrm{R}=\mathrm{Me}, \mathrm{Bu}, \mathrm{Oc})$, for different chain lengths of PROZO, reaction solvents (acetonitrile, chloroform, and water), and macromonomer concentrations.

\section{EXPERIMENTAL}

\section{Materials}

$\mathrm{CH}_{3} \mathrm{CN}$ was purified by distillation after refluxing with $\mathrm{P}_{2} \mathrm{O}_{5}$. $\mathrm{Et}_{2} \mathrm{O}$ was distilled over sodium wire. Commercial reagents 2-methyl-2-oxazoline (MeOZO) and methacryloyl chloride were purified by distillation. 2- $n$-Butyl- 


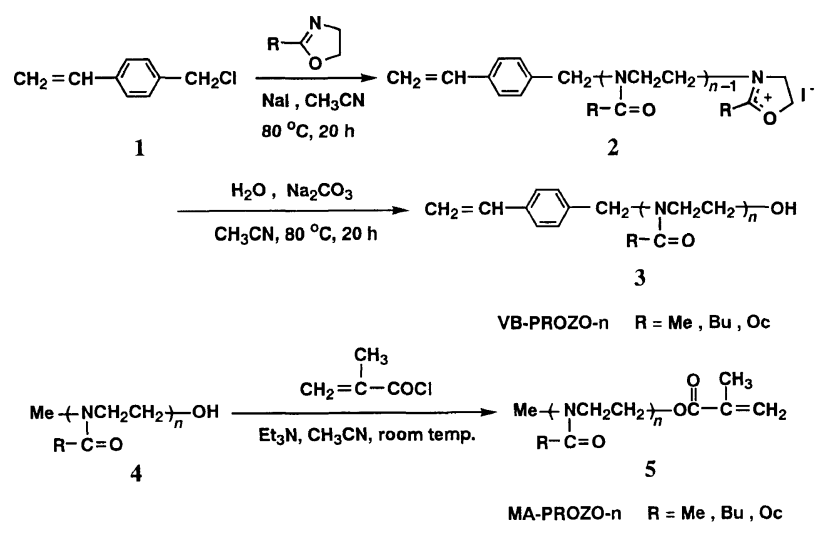

Scheme 1.

2-oxazoline $(\mathrm{BuOZO}),{ }^{11}$ 2-n-octyl-2-oxazoline (OcO$\mathrm{ZO}),{ }^{11}$ and $p$-vinylbenzyl chloride $(\mathrm{VBC})^{12}$ were prepared according to the literature. Commercial initiator 2,2'-azobis(2-amidinopropane) dihydrochloride (V-50) and deuterated solvents $\mathrm{CD}_{3} \mathrm{CN}, \mathrm{CDCl}_{3}$, and $\mathrm{D}_{2} \mathrm{O}$ were used as received. 2,2'-Azobis(isobutyronitrile) (AIBN) was recrystallized from $\mathrm{MeOH}$.

\section{Measurements}

${ }^{1} \mathrm{H}$ NMR spectra were recorded on a JEOL JNM FX60Q FT NMR spectrometer at $24^{\circ} \mathrm{C}$ with tetramethylsilane as standard. GPC was performed using a SHIMADZU LC-10AD chromatograph equipped with a SHIMADZU RID-6A RI detector. GPC columns, SHODEX AC-803 and JASCO FINE PACK GEL101(Column A; $M_{n}$ at exclusion limit, $7 \times 10^{4}$ ), or two columns of TOSOH TSKgel $\mathrm{GMH}_{\mathrm{HR}} \mathrm{M}$ (Column B; $M_{n}$ at exclusion limit, $4 \times 10^{6}$ ) were connected in series, and $\mathrm{CHCl}_{3}$ was used as an eluent at a flow rate of $0.8 \mathrm{~mL} \mathrm{~min}^{-1}$ in the former, and $N, N$-dimethylformamide (DMF) was used at the same flow rate at $60^{\circ} \mathrm{C}$ in the latter. Surface tension of aqueous macromonomer solutions was measured by a KYOWA CBVP-A3 tensiometer (Wilhelmy method).

\section{Macromonomers}

$p$-Vinylbenzyl(VB)-terminated PROZO (VB-PROZO) macromonomers (3) and MA-terminated PROZO(MAPROZO) macromonomers (5) were prepared by the living polymerization of 2-alkyl-2-oxazoline (ROZO) (Scheme 1).

ROZO was heated with $\mathrm{VBC}$ and $\mathrm{NaI}$ as initiator in $\mathrm{CH}_{3} \mathrm{CN}$ to give rise to living PROZO (2), ${ }^{2 \mathrm{a}}$ which was hydrolyzed to alcohol (3). Macromonomers 3 were purified by reprecipitation from $\mathrm{CHCl}_{3}$ solution with $\mathrm{Et}_{2} \mathrm{O}(\mathrm{R}=\mathrm{Me})$ or hexane $(\mathrm{R}=\mathrm{Bu}$ and $\mathrm{Oc})$ as nonsolvents. For preparation of MA-PROZO macromonomers (5), ROZO was polymerized with methyl tosylate as an initiator and the living PROZO was hydrolyzed to give a PROZO-alcohol (4), which was acylated with methacryloyl chloride. ${ }^{3} \mathbf{5}$ was purified similarly to $\mathbf{3}$.

The results are shown in Table I. Code names of the macromonomers are VB-PROZO- $n$ and MA-PROZO- $n$, whose $n$ is $D P_{n}$ of ROZO. $M_{n}$ of $\mathbf{3}$ and $\mathbf{5}$ was determined by ${ }^{1} \mathrm{H}$ NMR and GPC. In ${ }^{1} \mathrm{H}$ NMR, signal integration ratios of $\mathrm{NCH}_{2}$ protons $(\delta 3.4-3.6)$ to phenylene protons $(\delta 7.19-7.47)$ in 3 and $\mathrm{NCH}_{3}$ protons $(\delta 3.0)$ at $\omega$ ends
Table I. Macromonomers of poly(2-alkyl-2-oxazoline)(PROZO)

\begin{tabular}{|c|c|c|c|c|c|}
\hline \multirow{2}{*}{ Macromonomer $^{a}$} & \multicolumn{2}{|c|}{$M_{n}$} & \multirow{2}{*}{$D P_{n}^{\mathrm{b}}$} & \multirow{2}{*}{$\frac{M_{w}{ }^{\mathrm{b}}}{M_{n}}$} & \multirow{2}{*}{$F^{\mathrm{c}}$} \\
\hline & NMR & GPC & & & \\
\hline VB-PMeOZO-3 & 470 & 440 & 3.3 & 1.31 & 1.00 \\
\hline VB-PMeOZO-13 & 1230 & 1140 & 12.8 & 1.10 & 1.00 \\
\hline VB-PMeOZO-34 & 3030 & 2910 & 34.0 & 1.16 & 1.00 \\
\hline VB-PBuOZO-13 & 1810 & 1760 & 13.2 & 1.12 & 1.00 \\
\hline VB-PBuOZO-24 & 3120 & 3190 & 23.5 & 1.15 & 1.00 \\
\hline VB-POcOZO-3 & 730 & 680 & 3.0 & 1.34 & 1.00 \\
\hline VB-POcOZO-16 & 3100 & 3010 & 15.7 & 1.17 & 1.00 \\
\hline MA-PMeOZO-8 & 800 & 830 & 8.2 & 1.18 & 1.00 \\
\hline MA-PMeOZO-15 & 1340 & 1410 & 14.6 & 1.12 & 0.98 \\
\hline MA-PMeOZO-32 & 2820 & 2730 & 32.0 & 1.17 & 0.99 \\
\hline MA-PBuOZO-7 & 1010 & 960 & 7.2 & 1.15 & 1.00 \\
\hline MA-PBuOZO-14 & 1920 & 1840 & 14.3 & 1.13 & 1.00 \\
\hline MA-PBuOZO-34 & 4390 & 4020 & 33.7 & 1.19 & 0.99 \\
\hline MA-POcOZO-4 & 800 & 880 & 3.8 & 1.30 & 1.00 \\
\hline MA-POcOZO-8 & 1660 & 1740 & 8.5 & 1.16 & 1.00 \\
\hline MA-POcOZO-11 & 2140 & 2230 & 11.1 & 1.17 & 1.00 \\
\hline
\end{tabular}

${ }^{a}$ POcOZO: poly(2-n-octyl-2-oxazoline). ${ }^{\mathrm{b}}$ Determined by GPC ${ }^{c} F$ : functionality of polymerizable end groups determined by ${ }^{1} \mathrm{H}$ NMR.

in 5 gave macromonomer chain length $n\left(D P_{n}\right)$, from which $M_{n}$ was calculated. GPC was measured with GPC columns SHODEX AC-803 and JASCO FINE PACK GEL-101 connected in series (Column $\mathrm{A}$ ) in $\mathrm{CHCl}_{3}$ as eluent using $\mathrm{PMeOZO}$ standards prepared by polymerization of $\mathrm{MeOZO}$ by MeOTs as initiator. Molecular weight distribution was generally narrow reflecting the living nature of the polymerization; $M_{w} / M_{n}=1.10-1.34$. Functionality $(F)$, i.e., the number of vinylbenzyl or methacryloyl groups per molecules of macromonomers $\mathbf{3}$ and $\mathbf{5}$ was evaluated as follows. $F$ of $\mathbf{3}$ was calculated from signal integration ratios of phenylene protons $(\delta$ $7.19-7.47)$ to $\mathrm{OCH}_{2}$ protons $(\delta 4.07)$ at $\omega$ ends, and that of 5 was calculated from signal integration ratios of both vinyl protons ( $\delta 5.60-6.03)$ of methacryloyl groups to $\mathrm{NCH}_{3}$ protons $(\delta 3.0)$ at $\omega$ ends.

\section{Polymerization}

Radical polymerization of macromonomers was carried out under $\mathrm{Ar}$ in organic solvents $\left(\mathrm{CD}_{3} \mathrm{CN}, \mathrm{CDCl}_{3}\right)$ or $\mathrm{D}_{2} \mathrm{O}$ in a sealed $5 \mathrm{~mm} \phi$ NMR tube at $60^{\circ} \mathrm{C}$, using AIBN (in organic solvents) or $\mathrm{V}-50$ (in $\mathrm{D}_{2} \mathrm{O}$ ) as initiator. Conversion of macromonomers was mainly determined by change of signal integration ratios in ${ }^{1} \mathrm{H}$ NMR of the reaction mixture, i.e., $\mathrm{CH}_{2}$ signal $(\delta 5.80$, $5.25)$ of vinyl group to $\mathrm{CH}_{2}$ signal $(\delta 4.28)$ of benzyl group in VB-PROZO, and $\mathrm{CH}_{2}$ signal $(\delta 5.60-6.03)$ of vinyl group to $\mathrm{CH}_{2}$ signal $(\delta 4.24)$ of $\mathrm{OCH}_{2}$ signal in MA-PROZO. For confirmation of NMR, macromonomer conversion was determined also by GPC in the homopolymerization of VB-PMeOZO-13 and MA-PMeOZO-15 in $\mathrm{CD}_{3} \mathrm{CN}$. The reaction solutions were evaporated in vacuo to dryness to give mixtures of poly(macromonomer)s and unreacted macromonomers, which were analyzed by GPC using two columns of TOSOH TSKgel $\mathrm{GMH}_{\mathrm{HR}} \mathrm{M}$ connected in series(Column B) in DMF as eluent. Conversion $p$ of the macromonomer was calculated from eq 1 under the assumption that peak area per ROZO unit by RI detector is equal for a macromonomer and a poly(macromonomer). 




Figure 1. Time versus conversion plots in the polymerization of MA-PMeOZO-15 ( $\bigcirc$ by NMR, $\square$ by GPC), MA-PMeOZO-32 ( $\triangle$ by NMR), VB-PMeOZO-13 ( by NMR, $\nabla$ by GPC), and VB-PMeOZO-34 ( $\Delta$ by NMR) in $\mathrm{CD}_{3} \mathrm{CN}$ at $60^{\circ} \mathrm{C}$ with $[M]_{0}=44$ $\mathrm{mmol} \mathrm{L}-1$ and $[I]_{0}=2.20 \mathrm{mmol} \mathrm{L}^{-1}$

$$
p=A_{\mathrm{p}} /\left(A_{\mathrm{m}}+A_{\mathrm{p}}\right)
$$

where $A_{\mathrm{m}}$ is the peak area of a macromonomer, while $A_{\mathrm{p}}$, that of poly(macromonomer). Polymerization rate $R_{\mathrm{p}}$ was obtained from the initial slope of time-conversion plots. After polymerization reaction mixtures were analyzed by GPC using the Column B in the same manner as described above using polystyrene as standard.

In Figure 1, time versus conversion plots of polymerization of PMeOZO macromonomers in $\mathrm{CD}_{3} \mathrm{CN}$ are shown. Plots given by GPC in VB-PMeOZO-13 and MA-PMeOZO-13 agree well with those by ${ }^{1} \mathrm{H}$ NMR. Therefore, NMR was mainly used for determining conversion.

\section{RESULTS AND DISCUSSION}

\section{Polymerization Rate}

PBuOZO macromonomers were insoluble in $\mathrm{D}_{2} \mathrm{O}$, and POcOZO macromonomers were insoluble in $\mathrm{D}_{2} \mathrm{O}$ and $\mathrm{CD}_{3} \mathrm{CN}$. Both macromonomers were readily soluble in $\mathrm{CDCl}_{3}$. PMeOZO macromonomers were soluble in three solvent. The resulting poly(macromonomer)s were insoluble in $\mathrm{CDCl}_{3}$.

Time versus conversion plots in Figure 1 suggest that polymerization proceeds faster with chain length $(n)$ for VB-PMeOZO and MA-PMeOZO macromonomers within the range of $n$ examined. The apparent rates of polymerization $\left(R_{\mathrm{p}}\right)$ from those curves (Table II) were higher than that for model small monomers (VBPMeOZO-3), and increased with $n$. Time versus conversion plots in organic solvents leveled off with reaction time, ascribable to dead-end polymerization because of low concentrations of the monomers. ${ }^{13}$ In the radical polymerization of vinylbenzyl-ended poly(ethylene oxide) macromonomers with chain length $n$ of $32-45$ in benzene reported by Ito et al., $R_{\mathrm{p}}$ was higher than for model monomers with $n$ of $4 .{ }^{5 b}$ Our results seem basically consistent with their data. In MA and VB-ended polystyrene macromonomers, $R_{\mathrm{p}}$ was observed to be larger for the macromonomers with longer chain length than for shorter chain length by Tsukahara et al., which was explained by higher gel effect. ${ }^{5 a}$

In the polymerization of macromonomers, higher viscosity and segment density than the ordinary po-
Table II. Polymerization rates of $\mathrm{PMeOZO}$ and $\mathrm{PBuOZO}$ macromonomers in organic solvents ${ }^{\mathrm{a}}$

\begin{tabular}{rlll}
\hline & & & \\
Entry & Macromonomer & $\begin{array}{c}\text { Polymerization } \\
\text { solvent }\end{array}$ & $R_{\mathrm{p}} \times 10^{7 \mathrm{~b}}$ \\
\cline { 4 - 4 } & & $\mathrm{mol} \mathrm{L}^{-1} \mathrm{~s}^{-1}$ \\
\hline 1 & VB-PMeOZO-3 & $\mathrm{CD}_{3} \mathrm{CN}$ & 0.74 \\
2 & VB-PMeOZO-13 & $\mathrm{CD}_{3} \mathrm{CN}$ & 1.09 \\
3 & VB-PMeOZO-34 & $\mathrm{CD}_{3} \mathrm{CN}$ & 2.22 \\
4 & VB-PBuOZO-13 & $\mathrm{CD}_{3} \mathrm{CN}$ & 4.45 \\
5 & VB-PBuOZO-13 & $\mathrm{CDCl}_{3}$ & 0.84 \\
6 & VB-PBuOZO-24 & $\mathrm{CD}_{3} \mathrm{CN}$ & 5.85 \\
7 & VB-POcOZO-3 & $\mathrm{CDCl}_{3}$ & 11.30 \\
8 & VB-POcOZO-16 & $\mathrm{CDCl}_{3}$ & 19.73 \\
9 & MA-PMeOZO-8 & $\mathrm{CD}_{3} \mathrm{CN}$ & 1.00 \\
10 & MA-PMeOZO-15 & $\mathrm{CD}_{3} \mathrm{CN}$ & 3.34 \\
11 & MA-PMeOZO-32 & $\mathrm{CD}_{3} \mathrm{CN}$ & 5.64 \\
12 & MA-PBuOZO-7 & $\mathrm{CD}_{3} \mathrm{CN}$ & 1.64 \\
13 & MA-PBuOZO-14 & $\mathrm{CD}_{3} \mathrm{CN}$ & 7.47 \\
14 & MA-PBuOZO-14 & $\mathrm{CDCl}_{3}$ & 3.50 \\
15 & MA-PBuOZO-34 & $\mathrm{CD}_{3} \mathrm{CN}$ & 9.41 \\
16 & MA-POcOZO-4 & $\mathrm{CDCl}_{3}$ & 2.11 \\
17 & MA-POcOZO-8 & $\mathrm{CDCl}_{3}$ & 0.95 \\
18 & MA-POcOZO-11 & $\mathrm{CDCl}_{3}$ & 0.68 \\
& & & \\
& & &
\end{tabular}

${ }^{\mathrm{a}}[M]_{0}=44 \mathrm{mmol} \mathrm{L}^{-1} ; \quad[I]_{0}=2.2 \mathrm{mmol} \mathrm{L}^{-1} ;$ temperature, $60{ }^{\circ} \mathrm{C}$. ${ }^{\mathrm{b}}$ Initial rate of polymerization.

lymerization system must depress translational diffusion and segmental diffusion of growing sites and macromonomers, and mutual diffusion of growing sites. ${ }^{14}$ These effects are expected to decrease propagation and termination rates. Bimolecular termination reactions between growing ends with high segment density should be strongly suppressed by depression of diffusion. ${ }^{14}$

Radical polymerization rate $R_{\mathrm{p}}$ in ordinary monomers is defined by ${ }^{15}$

$$
R_{\mathrm{p}}=k_{\mathrm{p}}\left(2 f k_{\mathrm{d}} / k_{\mathrm{t}}\right)^{0.5}[M][I]^{0.5}
$$

where $k_{\mathrm{p}}, k_{\mathrm{t}}$, and $k_{\mathrm{d}}$ are rate constants for propagation, termination, and initiator decomposition, respectively, and $f$ is initiator efficiency. In polymerization of macromonomers, decrease of termination reactivity results in increase in polymerization rate. ${ }^{5 b, 14}$ Tsukahara et al. reported that $k_{\mathrm{p}}$ and $k_{\mathrm{t}}\left(\mathrm{L} \mathrm{mol}^{-1} \mathrm{~s}^{-1}\right)$ of radical polymerization of MA-terminated polystyrene macromono$\operatorname{mer}\left(M_{n}=4400\right)$ were $1 / 20$ and $1 / 3000$ of those of MMA, respectively. ${ }^{5 \mathrm{a}}$ When $R_{\mathrm{p}}$ of $\mathrm{PMeOZO}$ and $\mathrm{PBuOZO}$ macromonomers of similar chain length $(n)$ are compared as shown in Table II, the polymerization of PBuOZO macromonomers is faster than that of $\mathrm{PMeOZO}$ macromonomers for VB and MA polymerizable groups (entry 2, 4, and 10,13). With similar chain length $(n)$, molecular weight of $\mathrm{PBuOZO}$ macromonomer is higher than that of PMeOZO macromonomers. PBuOZO macromonomers with lower molecular weight polymerize faster than PMeOZO macromonomers with higher molecular weight (entry 4, 3 and 13, 11). PROZO macromonomers with pentanoyl side chains can be considered to possess higher reactivity than macromonomers with acetyl side chains in these reaction conditions and ranges of $n$. This can be mainly ascribed to depress termination caused by retarding translational diffusion and interpenetration of propagating sites with highly increased segment density (Figure 2).

Comparing reactivity of polymerizable end groups, 


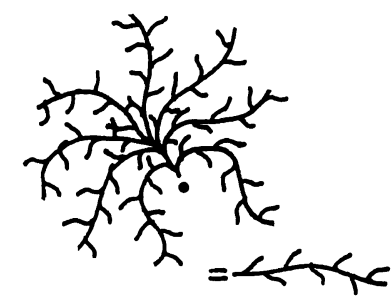

Figure 2. Models for growing chains and macromonomers.

MA-terminated macromonomers exhibited higher initial rates of polymerization than VB-terminated macromonomers with same alkyl groups (R) and similar chain length $(n)$. This agrees with results for MMA and styrene monomers. ${ }^{15}$

Polymerizability of POcOZO macromonomers with longer branch (pelargonoyl group) was examined and compared with that of PBuOZO macromonomers using $\mathrm{CDCl}_{3}$ as solvent, since POcOZO macromonomers were insoluble in $\mathrm{CD}_{3} \mathrm{CN}$. The results are given in Table II. The polymerizability of $\mathrm{PBuOZO}$ macromonomers in $\mathrm{CDCl}_{3}$ is lower than in $\mathrm{CD}_{3} \mathrm{CN}$ (entry 4,5 and 13,14 ). $\mathrm{PBuOZO}$ macromonomers were more readily soluble in $\mathrm{CDCl}_{3}$ than in $\mathrm{CD}_{3} \mathrm{CN}$, forming transparent solutions in $\mathrm{CDCl}_{3}$ but slightly cloudy solution in $\mathrm{CD}_{3} \mathrm{CN}$. Consequently, lower rates in $\mathrm{CDCl}_{3}$ can be explained as follows: higher solubility of $\mathrm{PBuOZO}$ chains in $\mathrm{CDCl}_{3}$ increases the coil size of growing chain than in $\mathrm{CD}_{3} \mathrm{CN}$, favoring interpenetration between growing sites to lead to inefficient retardation of termination reaction. In VB-ended macromonomers, even VB-POcOZO-3 of shorter chain length $(n)$ and lower molecular weight exhibited significantly higher initial rate $\left(11.30 \times 10^{-7}\right.$ mol L ${ }^{-1} \mathrm{~s}^{-1}$ ), being polymerized faster than VBPBuOZO-13 of longer chain length and of higher molecular weight. $R_{\mathrm{p}}$ of VB-POcOZO-16 was further higher, i.e., $19.73 \times 10^{-7} \mathrm{~mol} \mathrm{~L}^{-1} \mathrm{~s}^{-1}$. Such high $R_{\mathrm{p}}$ of VB-POcOZO macromonomers are very noticeable in the present polymerization in organic solvents. The reason for these results can be considered basically the same as the reactivity of $\mathrm{PBuOZO}$ macromonomers as described above, and further acceleration of reactivity in VB-POcOZO macromonomers must be achieved by stronger depression of termination caused by highly increased segment density around growing sites (Figure 2). MA-terminated POcOZO macromonomers showed quite different tendency. $R_{\mathrm{p}}$ of MA-POcOZO-4, whose chain length is shortest in MA-POcOZO macromonomers, is $2.11 \times 10^{-7} \mathrm{~mol} \mathrm{~L}^{-1} \mathrm{~s}^{-1}$, being lower than that of MA-PBuOZO-14. $R_{\mathrm{p}}$ of MA-POcOZO macromonomers decreased with increase in chain length $(n)$. In various macromonomers, MA-ended macromonomers are usually polymerized with higher reactivity than VB-ended ones as already discussed. The reverse results were observed in POcOZO macromonomers. Decrease in polymerizability of MA-POcOZO macromonomers may be explained as follows: in MA-POcOZO macromonomers or their polymer radicals, linkages from vinyl groups or growing ends to POcOZO segments are wholly single bonds that are flexible in contrast to VB-POcOZO macromonomers or their radicals, and accordingly steric effect of the long acyl chains (pelargonoyl groups) seems highly exerted at reaction

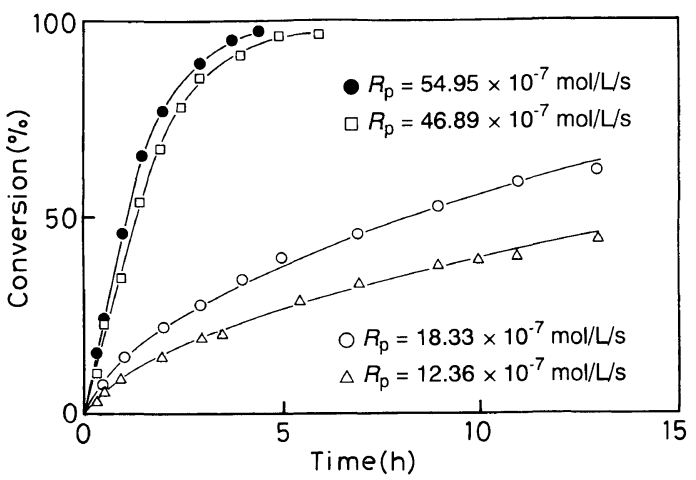

Figure 3. Time versus conversion plots in the polymerization of MA-PMeOZO-32 (O), MA-PMeOZO-15 ( $\square$ ), VB-PMeOZO-34 (O), and VB-PMeOZO- $13(\triangle)$ in $\mathrm{D}_{2} \mathrm{O}$ at $60^{\circ} \mathrm{C}$ with $[M]_{0}=44 \mathrm{mmol} \mathrm{L}^{-1}$ and $[I]_{0}=0.44 \mathrm{mmol} \mathrm{L}^{-1}$. Conversion was followed by NMR.



Figure 4. Relationship of surface tension $(\gamma)$ to solution concentration in macromonomers; MA-PMeOZO-32 (O), VB-PMeOZO-34 $(\triangle)$, MA-PMeOZO-15 ( $\square$ ), and VB-PMeOZO-13 (○)

sites to retard strongly propagation reactions. In the radical polymerization of $\mathrm{VB}$ and $\mathrm{MA}$-ended poly(ethylene oxide) macromonomers, bulky alkyl groups such as $n$-octyl groups at $\omega$ ends show little effect on polymerizability. ${ }^{5 b}$

The reactivity of radical polymerization of $\mathrm{PMeOZO}$ macromonomers in $\mathrm{D}_{2} \mathrm{O}$ increased enormously, compared with $\mathrm{CD}_{3} \mathrm{CN}$, as shown in Figure 3. For VBPMeOZO-13 and 34, ratios of $R_{\mathrm{p}}$ in $\mathrm{D}_{2} \mathrm{O}$ to that in $\mathrm{CD}_{3} \mathrm{CN}$ were 11.3 and 9.27 , respectively. Ito et al. proposes the micellar polymerization of poly(ethylene oxide) macromonomers in water. ${ }^{5 b}$ The polymerization rate was extremely higher than that in benzene, mainly due to increased propagation and decreased termination. ${ }^{16}$ VB-PMeOZO macromonomers act also as emulsifiers in soap-free emulsion copolymerization with styrene in water. $^{7 b}$ To examine the ability of micelle formation of $\mathrm{PMeOZO}$ macromonomers in water, surface tension $(\gamma)$ of aqueous solutions of VB and MA-ended macromonomers ( $n$ : $13-34)$ was measured. $\gamma$ of $1.0 \mathrm{wt} \%$ solutions of VB-PMeOZO-13, VBPMeOZO-34, MA-PMeOZO-15, and MA-PMeOZO-32 were $50.5,54.8,51.6$, and 55.8 dynes $\mathrm{cm}^{-1}$, respectively, exhibiting surfactant properties of PMeOZO macromonomers and were lower at $n$ of $13-15$ than 32-34. Critical micelle concentrations $(\mathrm{cmc})$ were observed at $0.60-0.72 \mathrm{wt} \%$ (Figure 4). Those results show that the PMeOZO macromonomers should aggregate in aqueous 


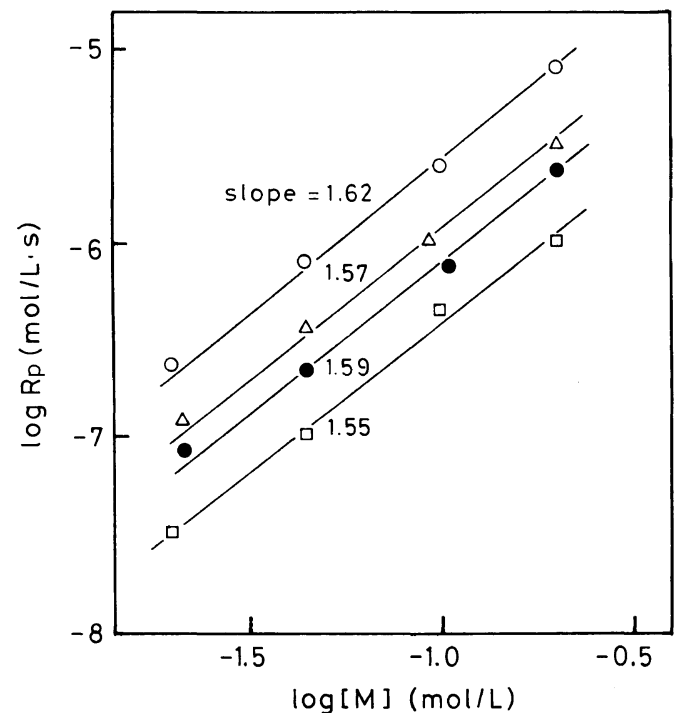

Figure 5. $\log -\log$ plots of $R_{\mathrm{p}}$ versus $[M]$ in the polymerization of MA-PBuOZO-14 (O), MA-PMeOZO-15 ( $\triangle$ ), VB-PMeOZO-34 (๑), and VB-PMeOZO-13 $(\square)$ in $\mathrm{CD}_{3} \mathrm{CN}$ at $60^{\circ} \mathrm{C}$ with $[I]_{0}=2.20 \mathrm{mmol}$ $\mathrm{L}^{-1}$.

solution to form micelles in the range of monomer concentrations in actual polymerization solutions. Reactivities of propagation and termination should increase and decrease, respectively, to accelerate polymerization.

For MA-PMeOZO-15 and 32, ratios of $R_{\mathrm{p}}$ in $\mathrm{D}_{2} \mathrm{O}$ to that in $\mathrm{CD}_{3} \mathrm{CN}$ were 14.1 and 9.8 , respectively. The polymerization of MA-PMeOZO macromonomers in $\mathrm{D}_{2} \mathrm{O}$ can also be taken as micellar polymerization and was observed to proceed at higher rate than that of VB-PMeOZO macromonomers. Ratios of $R_{\mathrm{p}}$ of MAPMeOZO- $n$ to that of VB-PMeOZO- $n$ at similar $n$ in $\mathrm{D}_{2} \mathrm{O}$ were higher than in $\mathrm{CD}_{3} \mathrm{CN}$. It is not easy to explain this trend, because $k_{\mathrm{p}}$ and $k_{\mathrm{t}}$ are unknown. The enhancing effect of water solvent on polymerization rate was observed to be higher for chain length $n$ around 13, probably due to fitting for micelle formation of macromonomers as described above.

\section{Concentration Dependence of Polymerization Rate}

The radical polymerization rate of PROZO macromonomers is influenced by macromonomer chain length (n) and carbon number of alkyl chains. The effects of concentrations of monomer and initiator on the present polymerization system were examined.

The effects of monomer concentrations on the polymerization rate $R_{\mathrm{p}}$ are shown in Figure 5. Whole plots of $\log [M]$ versus $\log R_{\mathrm{p}}$ gave straight lines. Reaction orders of macromonomer concentration $[M]$ obtained from the slopes of the straight lines are listed in Table III. The values given in polymerization of $\mathrm{PMeOZO}$ macromonomers in $\mathrm{CD}_{3} \mathrm{CN}$ are in the range of $1.55-1.63$, and higher than for convensional small monomers in radical polymerization.

Tsukahara et al. ${ }^{14 a}$ and Ito et al. ${ }^{5 b}$ obtained kinetic orders of $[M]$ to be 2.1 and $1.40-1.49$ for the MA-ended polystyrene macromonomer of a $M_{n}$ of 12400 and VBended poly(ethylene oxide) macromonomers of a molecular weight around 1200 respectively, in the homopolymerization in organic solvents. They explained the
Table III. Reaction orders of macromonomer concentrations ${ }^{\mathrm{a}}$

\begin{tabular}{llc}
\hline Macromonomer & $\begin{array}{c}\text { Polymerization } \\
\text { solvent }\end{array}$ & Kinetic order $^{\mathbf{b}}$ \\
\hline VB-PMeOZO-13 & $\mathrm{CD}_{3} \mathrm{CN}$ & 1.55 \\
VB-PMeOZO-34 & $\mathrm{CD}_{3} \mathrm{CN}$ & 1.59 \\
VB-PBuOZO-13 & $\mathrm{CD}_{3} \mathrm{CN}$ & 1.61 \\
MA-PMeOZO-15 & $\mathrm{CD}_{3} \mathrm{CN}$ & 1.57 \\
MA-PMeOZO-32 & $\mathrm{CD}_{3} \mathrm{CN}$ & 1.63 \\
MA-PBuOZO-14 & $\mathrm{CD}_{3} \mathrm{CN}$ & 1.62 \\
VB-PBuOZO-13 & $\mathrm{CDCl}_{3}$ & 1.65 \\
VB-POcOZO-16 & $\mathrm{CDCl}_{3}$ & 1.72 \\
MA-PBuOZO-14 & $\mathrm{CDCl}_{3}$ & 1.68 \\
MA-POcOZO-11 & $\mathrm{CDCl}_{3}$ & 1.73 \\
VB-PMeOZO-13 & $\mathrm{D}_{2} \mathrm{O}$ & 1.04 \\
MA-PMeOZO-15 & $\mathrm{D}_{2} \mathrm{O}$ & 0.97 \\
\hline
\end{tabular}

${ }^{\mathrm{a}}[M]_{0}=44 \mathrm{mmol} \mathrm{L}^{-1} ; \quad[I]_{0}=2.2 \mathrm{mmol} \mathrm{L}^{-1} ;$ temperature, $60^{\circ} \mathrm{C}$. ${ }^{\mathrm{b}}$ Kinetic order of $[M]$.



Figure 6. Log-log plots of $R_{\mathrm{p}}$ versus $[M]$ in the polymerization of MA-PMeOZO-15 (O) and VB-PMeOZO- $13(-)$ in $\mathrm{D}_{2} \mathrm{O}$ at $60^{\circ} \mathrm{C}$ with $[I]_{0}=0.44 \mathrm{mmol} \mathrm{L}^{-1}$.

higher kinetic orders on the basis of increased viscosity of polymerization media by higher concentrations of macromonomers, resulting in retardation of termination reactions. Kinetic orders in the present polymerization can be interpreted by the same gel effect, because of similar $M_{n}$ of the PROZO macromonomers for poly(ethylene oxide) macromonomers. In macromonomers with longer acyl groups $(\mathrm{R}=\mathrm{Bu}, \mathrm{Oc})$, slightly higher kinetic orders were observed, probably due to stronger depression in termination brought about by increased suppression of diffusions with segment density of growing radicals.

Log- $\log$ plots of $R_{\mathrm{p}}$ versus $[M]$ in the polymerization of VB-PMeOZO-13 and MA-PMeOZO-15 in $\mathrm{D}_{2} \mathrm{O}$ also gave straight lines (Figure 6), showing higher rates than in organic solvents. The kinetic orders of $[M]$ were close to 1.0 , as normally observed for convensional small monomers. Under the assumption that polymerization in water proceeds in micelles, monomer concentration should affect the number of micelles in reaction system. There would be no influence on the diffusion control in micelle. Thus, kinetic order is the same as the small monomer system.

The dependence of $R_{\mathrm{p}}$ of VB-PMeOZO-13 and MAPMeOZO-15 in $\mathrm{CD}_{3} \mathrm{CN}$ on initiator concentration $[I]$ 
at $[M]_{0}=44 \mathrm{mmol} \mathrm{L}^{-1}$ is given in Figure 7. Log-log plots of $R_{\mathrm{p}}$ versus [I] gave straight lines, from whose slopes kinetic orders were determined as 0.50 (MAPMeOZO-15) and as 0.54 (VB-PMeOZO-13). These orders appear compatible with the square root rule in eq 2. Thus, the result suggests that the termination in $\mathrm{CD}_{3} \mathrm{CN}$ involves mainly bimolecular reaction at the $[M]_{0}$.

\section{Molecular Weights of Poly(macromonomer)s}

After polymerization in NMR tube, molecular weights of produced poly(macromonomer)s were measured by GPC using an RI detector (Table IV). The values increased with macromonomer concentration under the same conditions of macromonomers (polymerizable end group and $\mathrm{R}$ ), probably due to depression of termination by increasing the viscosity of the polymerization system. Tsukahara et al. reported that molecular weight of a poly(macromonomer) is strongly affected by monomer

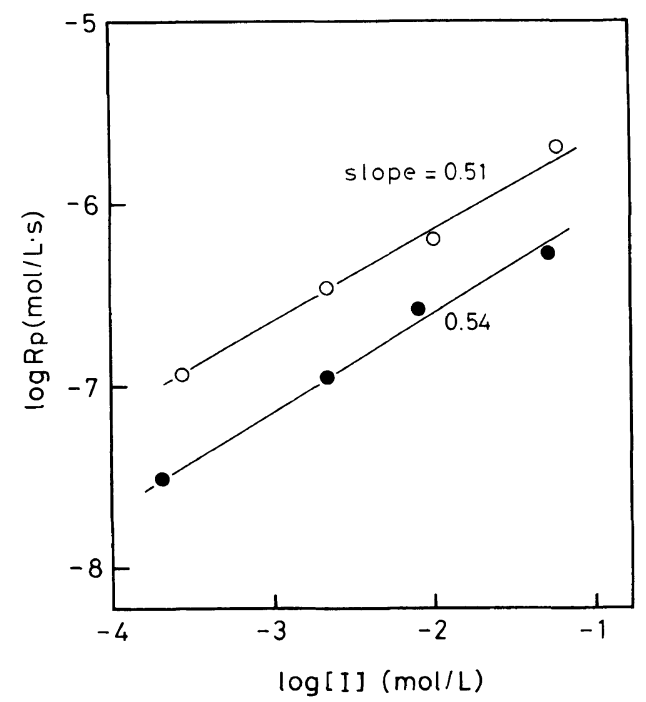

Figure 7. $\log -\log$ plots of $R_{\mathrm{p}}$ versus $[I]$ in the polymerization of MA-PMeOZO-14 (O) and VB-PMeOZO-13 $(\bullet)$ in $\mathrm{CD}_{3} \mathrm{CN}$ at $60^{\circ} \mathrm{C}$ with $[M]_{0}=44 \mathrm{mmol} \mathrm{L}^{-1}$. concentration in radical polymerization of polystyrene macromonomers. ${ }^{14}$ GPC of the product obtained from MA-PBuOZO-14 with $[M]_{0}$ of $200 \mathrm{mmol} \mathrm{L}^{-1}$ showed poly(macromonomer) peaks at $M_{n}$ of 90350 and 364000 (Figure 8 ). This can be explained by increased viscosity due to smaller polymer formed with consequent increase in the molecular weight of the polymer given by polymerization. Examination of MA-PBuOZO-34 with $[M]_{0}$ of $200 \mathrm{mmol} \mathrm{L}^{-1}$ exhibited no polymerization, probably due to remarkable depression of diffusion of growing radicals and macromonomers by increased viscosity and higher segment density. In contrast, VB-PMeOZO-34 polymerized even with $[M]_{0}$ of $200 \mathrm{mmol} \mathrm{L}^{-1}$ (Figure 5). The polymerization of $\mathrm{PBuOZO}$ macromonomers in $\mathrm{CDCl}_{3}$ gave poly(macromonomer)s of higher molecular weights than in $\mathrm{CD}_{3} \mathrm{CN}$. This can be explained by considering that the expanded coils of growing chains in $\mathrm{CDCl}_{3}$ favor penetration of macromonomers to accelerate propagation, resulting in increased molecular weights of poly(macromonomer)s.



Figure 8. GPC curves of reaction mixtures in the polymerization of MA-PBuOZO- 14 in $\mathrm{CD}_{3} \mathrm{CN}$ at $60^{\circ} \mathrm{C}$ (Runs 4 and 5). GPC: column, TOSOH TSKgel $\mathrm{GMH}_{\mathrm{HR}-\mathrm{M}}(\times 2)$; solvent, DMF $(\mathrm{LiCl})$; temp, $58^{\circ} \mathrm{C}$; flow rate, $0.8 \mathrm{~mL} \mathrm{min.}^{-1}$ Run $4:[M]_{0}=44 \mathrm{mmol} \mathrm{L}^{-1} ;[I]_{0}=2.2$ mmol L ${ }^{-1}$; reaction time, $130 \mathrm{~h}$. Run $5:[M]_{0}=200 \mathrm{mmol} \mathrm{L}^{-1}$; $[I]_{0}=2.2 \mathrm{mmol} \mathrm{L}^{-1}$; reaction time, $130 \mathrm{~h}$.

Table IV. Molecular weights of poly(macromonomer) $\mathrm{s}^{\mathrm{a}}$

\begin{tabular}{|c|c|c|c|c|c|c|c|}
\hline \multirow[b]{2}{*}{ Run } & \multirow[b]{2}{*}{ Macromonomer } & \multirow[b]{2}{*}{ Entry } & \multicolumn{3}{|c|}{ Polymerization $^{b}$} & \multirow[b]{2}{*}{$M_{n}$} & \multirow[b]{2}{*}{$D P_{n}$} \\
\hline & & & Solvent & {$[M]_{0}$} & Time & & \\
\hline 1 & MA-PBuOZO-7 & 12 & $\mathrm{CD}_{3} \mathrm{CN}$ & 44 & 140 & 54400 & 57 \\
\hline 2 & MA-PBuOZO-7 & - & $\mathrm{CD}_{3} \mathrm{CN}$ & 200 & 140 & 132000 & 137 \\
\hline 3 & MA-PBuOZO-14 & - & $\mathrm{CD}_{3} \mathrm{CN}$ & 20 & 140 & 38200 & 21 \\
\hline 4 & MA-PBuOZO-14 & 13 & $\mathrm{CD}_{3} \mathrm{CN}$ & 44 & 140 & 63500 & 35 \\
\hline \multirow[t]{2}{*}{5} & MA-PBuOZO-14 & - & $\mathrm{CD}_{3} \mathrm{CN}$ & 200 & 140 & 90400 & 49 \\
\hline & & & & & & 364000 & 198 \\
\hline 6 & MA-PBuOZO-34 & - & $\mathrm{CD}_{3} \mathrm{CN}$ & 100 & 140 & 116000 & 29 \\
\hline 7 & MA-PBuOZO-34 & - & $\mathrm{CD}_{3} \mathrm{CN}$ & 200 & 140 & $-^{c}$ & - \\
\hline 8 & VB-PBuOZO-13 & 4 & $\mathrm{CD}_{3} \mathrm{CN}$ & 44 & 140 & 32500 & 19 \\
\hline 9 & VB-PBuOZO-24 & 6 & $\mathrm{CD}_{3} \mathrm{CN}$ & 44 & 140 & 35400 & 11 \\
\hline 10 & MA-PBuOZO-14 & 14 & $\mathrm{CDCl}_{3}$ & 44 & 130 & 82700 & 45 \\
\hline 12 & MA-PMeOZO-15 & 10 & $\mathrm{CD}_{3} \mathrm{CN}$ & 44 & 140 & 33900 & 24 \\
\hline 13 & VB-PMeOZO-13 & 2 & $\mathrm{CD}_{3} \mathrm{CN}$ & 44 & 140 & 28700 & 25 \\
\hline 14 & MA-PMeOZO-15 & 21 & $\mathrm{D}_{2} \mathrm{O}$ & 44 & 6 & 48600 & 35 \\
\hline 15 & VB-PMeOZO-13 & 19 & $\mathrm{D}_{2} \mathrm{O}$ & 44 & 13 & 39700 & 35 \\
\hline
\end{tabular}

${ }^{\text {a }}$ Determined by GPC: column, TOSOH TSKgel $\mathrm{GMH}_{\mathrm{HR}} \mathrm{M}(\times 2)($ Column B); solvent, DMF( $\mathrm{LiCl})$; temp, $60^{\circ} \mathrm{C}$; flow rate, $0.8 \mathrm{~mL} \mathrm{~min}^{-1}$. ${ }^{\mathrm{b}}[I]_{0}=2.2 \mathrm{mmol} \mathrm{L}^{-1}$ (in organic solvents) and $0.44 \mathrm{mmol} \mathrm{L}^{-1}$ (in $\mathrm{D}_{2} \mathrm{O}$ ); temp, $60^{\circ} \mathrm{C}$. ${ }^{\mathrm{c}}$ No polymerization observed. 


\section{CONCLUSIONS}

Reactivity of radical homopolymerization of VBPROZO and MA-PROZO macromonomers was examined. In $\mathrm{CD}_{3} \mathrm{CN}$ or $\mathrm{CDCl}_{3}$, polymerization rate of the macromonomers increased with macromonomer chain length $(n)$ and/or in carbon number of alkyl groups (R), except in the case of MA-POcOZO- $n$. This can be explained that higher solution viscosity and segment density around the growing sites depress the translational diffusion and segmental diffusion of the growing chains to retard bimolecular termination.

In POcOZO macromonomers, polymerization rates of MA-type monomers were slower than for VB-type monomers, in contrast to present macromonomers and convensional small monomers and other macromonomers. With increase in $n$, polymerization rate of VBPOcOZO- $n$ increased, whereas that of MA-POcOZO- $n$ decreased. This may be interpreted that the growing ends or the vinyl groups of MA-POcOZO- $n$ are more susceptible to steric effects of $\mathrm{POcOZO}$ segment having long acyl chains than those of VB-POcOZO- $n$.

$\mathrm{PMeOZO}$ macromonomers were polymerized in $\mathrm{D}_{2} \mathrm{O}$ 9 to 14 times faster than $\mathrm{CD}_{3} \mathrm{CN}$, probably due to micelle formation of macromonomers.

Kinetic orders of monomer concentration were determined as 1.55 to 1.73 in organic solvents and closely 1.0 in water. The higher orders in organic solvents would result from increased retardation of termination caused by increased viscosity. The orders of initiator concentration were close to 0.5 , suggesting termination was mainly bimolecular reaction.

\section{REFERENCES}

1. (a) S. Kobayashi, Prog. Polym. Sci., 15, 751 (1990). (b) Y. Chujo and T. Saegusa, "Ring-Opening Polymerization," Hanser, Munich, 239 (1993). (c) K. Aoi and M. Okada, Prog. Polym. Sci., 21, 151 (1996). (d) D. A. Tomalia, H. R. Kricheldorf, Ed., "Handbook of Polymer Synthesis," Marcel Dekker, New York, N.Y., 747 (1991).

2. (a) S. Kobayashi, C. Merlesdorf, T. Tanabe, K. Matsuo, and T. Saegusa, Polym. Prepr., Jpn., 35, 248 (1986). (b) R. C. Schulz, and E. Schwarzenbach, Makromol. Chem., Macromol. Symp. 13/14, 495 (1988)

3. S. Kobayashi, E. Masuda, S. Shoda, and Y. Shimano, Macromolecules, 22, 2878 (1989).

4. H. Uyama and S. Kobayashi, Macromolecules, 24, 614 (1991).

5. (a) Y. Tsukahara, K. Tsutsumi, Y. Yamashita, and S. Shimada Macromolecules, 23, 5201 (1990). (b) K. Ito, K. Tanaka, H. Tanaka, G. Imai, S. Kawaguchi, and S. Itsuno, Macromolecules, 24, 2348 (1991). (c) I. Capek, M. Riga, and M. Akashi, Makromol. Chem., 193, 2843 (1992). (d) P. Rempp, P. Lutz, P. Masson, and E. Franta, Makromol. Chem., Suppl., 8, 3 (1984). (e) R. Asami and M. Takaki, Makromol. Chem., Suppl., 12, 163 (1985). (f) J. P. Kennedy and M. Hiza, J. Polym. Sci., Polym. Chem. Ed., 21, 1033 (1983)

6. E. Masuda, S. Kishiro, T. Kitayama, and K. Hatada, Polym. J., 23, 847 (1991).

7. (a) S. Kobayashi, H. Uyama, S. W. Lee, and Y. Matsumoto, $J$ Polym. Sci., Part A: Polym. Chem., 31, 3133 (1993). (b) S. Kobayashi, H. Uyama, and I. Yamamoto, Polym. Prepr., Jpn., 38, 1593 (1989).

8. S. Shoda, E. Masuda, M. Furukawa, and S. Kobayashi, J. Polym. Sci. Part A: Polym. Chem., 30, 1489 (1992).

9. (a) R. Asami and M. Takaki, Makromol. Chem., Suppl., 12, 163 (1985). (b) K. Ito, H. Tsuchida, A. Hayashi, T. Kitano, E Yamada, and T. Matsumoto, Polym. J., 17, 827 (1985). (c) M. Niwa and N. Hayashi, Macromolecules, 21, 1193 (1988). (d) M Akashi, I. Kirihira, and N. Miyauchi, Angew. Makromol. Chem., 132, 81 (1985). (e) C. G. Cameron and M. S. Chisholm, Polymer, 26, 437 (1985). (f) K. Mühlbach, V. Percec, and J. H. Wang, $J$. Polym. Sci., Polym. Chem. Ed., 25, 2605 (1987). (g) Y. Nabeshima and T. Tsuruta, Makromol. Chem., 190, 1635 (1989). (h) W. Radke and A. H. E. Müller, Makromol. Chem., Macromol. Symp., 54/55, 583 (1992). (i) J. P. Kennedy and C. Y. Lo, Polym. Bull., 13, 343 (1985). (j) P. Rempp, P. Lutz, P. Masson, and E. Franta, Makromol. Chem., Suppl., 13, 471 (1985).

10. (a) J. Sierra, E. Franta, and P. Rempp, Makromol. Chem., 182, 2603 (1981). (b) M. Takaki, R. Asami, and T. Kuwabara, Polym. Bull., 7, 521 (1982).

11. H. Witte and W. Seeliger, Liebigs Ann. Chem., 996 (1974).

12. T. Miyake and S. Tanimoto, Yuki Gosei Kagaku Kyokaishi, 30, 1489 (1992)

13. A. V. Tobolsky, J. Am. Chem. Soc., 80, 5927 (1958).

14. (a) Y. Tsukahara, K. Mizuno, A. Segawa, Y. Yamashita, Macromolecules, 22, 1546 (1989). (b) Y. Tsukahara, K. Tsutsumi, Y. Yamashita, and S. Shimada, Macromolecules, 22, 2869 (1989).

15. G. Odian, "Principles of Polymerization," 3rd ed, Wiley Interscience, New York, N.Y., 1991.

16. E. Nomura, K. Ito, A. Kajiwara, and M. Kamachi, Macromolecules, 30, 2812 (1997). 